\title{
POS MODERNIDADE, CIÊNCIA E DIREITO NO TERCEIRO MILENIO: PRIMEIRAS APROXIMAÇÕES
}

\author{
Profa Dra Maria de Lourdes Pinto de Almeida ${ }^{1}$ \\ Pedagoga e Historiadora formada pela Unicamp. Mestre e Doutora em História, Filosofia e \\ Educação pela Unicamp. \\ Pós-Doutora em Políticas Públicas pela USP. Pós-Doutoranda em Sociologia Política pela \\ Universidade de Salamanca. Docente Pesquisadora da Unicamp e da Faculdade Pitágoras. \\ Coordenadora Executiva do CEPEP - Pitágoras. \\ e-mail: malu04@uol.com.br
}

\section{Prof. Mestre Dirceu Pertuzzatti}

Formado em Direito pela PUCPR. Mestre em Ciências Jurídicas pela Univali - SC. Docente Pesquisador da Faculdade Pitágoras de Curitiba. Pesquisador do Grupo de Estudos e Pesquisas Pitágoras na área de concentração em Políticas Publicas e Direitos Humanos. e-mail: dirceupertuzzatti@uol.com.br

RESUMO: A virada do milênio trouxe uma série de inquietudes, incertezas e desafios para praticamente toda sociedade civil e política. Os estudiosos do direito, e em particular para aqueles que direcionam seus estudos na área do direito laboral, não ficaram a margem dessas novas perspectivas históricas. Nosso objetivo é, neste texto, debater a utilidade que o trabalho humano deve cumprir no processo de produção capitalista contemporâneo, onde cada vez menos se necessita de mão-de-obra humana. Pretendemos também estudar o contexto historico que está posto neste inicio de século XXI, rotulado por muitos de 'pos modernidade', ou era da irracionalidade, e engendrada nesta discussão, analisaremos a ciência jurídica, dita por muitos que é aquela que trata de realidades concretas. Sua contingência, outrora considerada empecilho ao seu caráter científico, é hoje tão-somente objeção Clássica. Entretanto, sabemos todos nós que o direito é por natureza conservador, sendo certo que a introdução de novos princípios e normas exigidos pelos reptos dos novos fatos é lenta e gradual. Há um descompasso freqüente entre a ordem jurídica e as transformações sociais, não devendo o direito, conforme a experiência tem demonstrado, distanciar-se com grande intensidade das transformações ocorridas no mundo do trabalho da sociedade capitalista. A metodologia que será utilizada para abordagem da temática é a dialética, pois estudaremos 0 fato inserido em seu contexto histórico e as influencias desse no objeto estudado. $O$ direito definido de forma grotesca é de difícil aplicação, gerando dúvidas, controvérsias e insegurança. Não deve assim ser exclusivamente conservadora, pois deve facilitar as inovações reclamadas pelas necessidades sociais.

1 Pedagoga e Historiadora formada pela UNICAMP. Mestre e Doutora em Historia, Filosofia e Educação pela FE da UNICAMP. Pos Doutora em Políticas Publicas pela USP. Pos Doutoranda em Sociologia Política pela Universidade de Salamanca. Docente Pesquisadora da UNICAMP e da Faculdade Pitágoras. Coordenadora Executiva do CEPEP - Pitágoras. Autora de vários livros editados pela Átomo e Alínea, www.atomoealinea.com.br

2 Formado em Direito pela PUCPR. Mestre em Ciências Jurídicas pela UNIVALI - SC. Docente Pesquisador da Faculdade Pitágoras de Curitiba. Pesquisador do Grupo de Estudos e Pesquisas Pitágoras na área de concentração em Políticas Publicas e Direitos Humanos. Membro do Conselho Editorial e Redator Chefe da Revista Virtual Pitágoras. 


\section{INTRODUÇAO}

"As idéias da classe dominante são, em cada época, as idéias dominantes; isto é, a classe que é a força material dominante da sociedade é, ao mesmo tempo, sua força espiritual dominante. A classe que tem à sua disposição os meios de produção material dispõe, ao mesmo tempo, dos meios de produção espiritual, o que faz com que a ela sejam submetidos, ao mesmo tempo e em média, as idéias daqueles aos quais faltam os meios de produção".

Se a única coisa certa sobre a pós-modernidade é a incerteza, devemos descobrir as forças sociais que produziram tal condição. Nesse sentido, a passagem do modernismo/fordista, (fixista) para o pós-modernismo flexível não constituiria em uma ruptura, mas sim, numa continuidade do movimento de acumulação de capital, que apenas descobriria novas formas de trabalhar suas crises - superprodução. Portanto, deve se compreender o "capital como um processo, e não uma coisa. É um processo de reprodução da vida social por meio da produção de mercadorias em que todas as pessoas do mundo capitalista avançado estão profundamente implicadas. O capitalismo seria uma força revolucionária da história mundial, uma força que reformula de maneira perpétua o mundo, criando configurações novas, e com freqüência, sobretudo inesperadas. A acumulação flexível se mostra, no mínimo como uma nova configuração, requerendo, nessa qualidade, que submetamos a escrutínio as suas manifestações com cuidados e seriedade exigidos, empregando, não obstante, os instrumentos teóricos concebidos por Marx.

Há um princípio do materialismo histórico que, ao mesmo tempo, o localiza e o generaliza, isto é, o torna válido dentro de determinado contexto e o torna "absoluto", quer dizer, válido para todos os contextos. Trata-se da idéia de que a verdade é filha de seu tempo, encontra-se situada, determinada por forças materiais - econômicas. Isso quer dizer que a metafísica, a ciência, o DIREITO, a ideologia etc., como aspectos superestruturais, dizem respeito à ordem da produção, em que se configuram os fatores materiais. Nesse sentido, o marxismo só poderia ser superado quando as condições históricas que o originaram fossem suprimidas. O marxismo seria uma ciência voltada para a emancipação da classe trabalhadora, assim como a economia política clássica teria sido a ciência da ascensão da burguesia. 
No entanto, na medida em que a classe trabalhadora representa o universal humano, no campo de luta no interior do capitalismo, numa nova etapa de organização social, ela deveria desaparecer e dar lugar a uma nova base social de hegemonia, a uma espécie de homem universal que de certo modo subsumiria a classe trabalhadora uma vez que as condições históricas que a geraram foram suprimidas. Esse princípio se inscreveria na própria dinâmica da história ou no movimento da superação das contradições. $\mathrm{Na}$ medida em que os homens tomam consciência dessas determinações, eles podem atuar - práxis - no sentido de transformar as relações de dominação suprimindo ativamente as bases nas quais elas se inserem, isto é, as relações de propriedade e de trabalho. Isso estaria em conformidade com a própria lógica inscrita nas relações materiais, no sentido de que as categorias são expressões das relações reais, sociais, que correspondem a um determinado modo de produção, sendo, portanto, tão pouco eternas quanto às relações que servem de expressão: Entende-se então que as categorias, mesmo as mais abstratas e gerais, são produtos de condições históricas determinadas, as relações existentes na sociedade mais desenvolvida permitem perceber as relações e a própria estrutura de todas as formas de sociedade passadas. Fica, portanto, patente que lógico e histórico são aspectos distintos e ao mesmo tempo inseparáveis, posto que a compreensão lógica é necessariamente histórica.

Constituiria numa anomalia um pensamento que surgisse desenraizado, sem a referência das condições sociais na qual estaria inserido seu produtor. Na verdade, o produtor é produto. É nesse sentido que o sujeito é a classe, é o social, não enquanto um agregado que pensa mais como conjunto de forças - interesses, formação da idiossincrasia. Essas forças moldam a consciência. É nesse sentido que as palavras de Marx, de que não é a consciência que molda o mundo mas o mundo que molda a consciência, faz-se presente. É em função desse suposto teórico que se expressa a idéia de que a filosofia restringiu-se a interpretar o mundo, sendo que o que importa é transformá-lo. Por outro lado, a consciência apresenta-se também como capacidade de antecipar mental do que se pretende realizar, ou seja, projeto, o que segundo Marx, tornaria o pior artesão melhor do que um animal, por mais 
habilidoso que este fosse. Esses pontos de vista aparentemente contrastantes revelam a própria condição do "homem" como produto e produtor.

O homem é sujeito, no sentido de que sua liberdade é determinada por uma situação, que ele não escolheu que, pelo contrário, o condicionou. Sua liberdade nasce da consciência de semelhante necessidade. Nesse sentido, a práxis diz respeito ao indivíduo, mas não se restringe o seu âmbito, pois ela é coletiva e somente enquanto tal é eficaz. A dimensão coletiva da atividade humana revela um indivíduo que, como tal, seria mera abstração, uma vez que suas determinações só se revelariam na concretude, no movimento do real, na totalidade.

Para se adotar uma atitude analítica e crítica diante das questões de Direito, é necessário ao jurista contemporâneo, acolher todas as contribuições teóricas, para nelas identificar as diretrizes comuns e essenciais, mediante um trabalho de reflexão e comparação, pois todas as concepções surgidas na história da ciência jurídica, por mais hostis que sejam, trazem sua parcela para o patrimônio geral do conhecimento científico-jurídico.

Exige-se, hodiernamente, ante o fato de se dar à normatividade do direito uma nova dimensão, que o jurista tenha um conhecimento sistemático do ordenamento jurídico, voltado à jusfilosofia, para fixar toda a riqueza da vida jurídica, essencialmente dinâmica, sob pena de ser absorvido pela mediocridade. No sentido filosófico, só merece a denominação de "ciência", o complexo de conhecimentos certos, ordenados e conexos entre si. A ciência é um saber metodicamente e rigorosamente fundado, demonstrado e sistematizado. Um conhecimento que não reúna as características próprias da investigação científica não é ciência, é matéria opinável, isto é, uma questão de opinião (o conhecimento de um objeto que tem uma pessoa sem preparo especial sobre ele e derivado da experiência da vida prática).

Já dissemos certa vez, e julgamos importante ressaltar novamente, que não podemos nos esquecer que na retaguarda do direito há uma ciência e, conseqüentemente, anos e anos de desenvolvimento social, crescimento doutrinário e jurisprudencial.

A prática científica insere-se em tal "contexto" de luta de classes. Considero, a partir dessas posições teóricas - marxismo e as fragmentarias correntes acomodadas no termo pós-moderno -, duas perspectivas 
contrastantes que buscam uma hegemonia no sentido de fundamentar um consenso em torno da atividade científica. Num primeiro prisma estaria às visões fragmentaristas, no outro as visões "integradoras". Onde uma vê rupturas e "esgarçamentos" contínuos e irremediáveis da realidade, a outra vê continuidades e totalizações se constituindo. Do ponto de vista político, prático, a primeira não acredita na possibilidade de uma ação centralizada, tal como propõem os defensores do planejamento estatal. A outra, pelo contrário nega a possibilidade de uma autocoordenação espontânea de uma multidão de agentes atuando conforme seus fins particularesii. É dentro desses dois quadros gerais ou panos de fundo, que se desenvolvem as respectivas "cenas".

O real torna-se susceptível aos mais diversos recortes e perspectivas de análise. Neste sentido, tudo é susceptível de uma história singular, sendo que haveria tantas histórias quantos recortes fossem possíveis. As séries independentes poderiam cruzar desviar-se mutuamente de rumo, mas não poderiam jamais ser compreendidas como variáveis de uma função integradora. Tudo é fragmentário e efêmero. Não há progresso, acumulação de civilidade. É como se a barbárie fosse sempre iminente. Na verdade, no mundo atual, os elementos irracionais, tribais, esotéricos, místicos, bem como a irrupção da violência material e simbólica são integrados ao modo de ser no capitalismo. Para os pós-modernos, esses contrastes que permitem uma convivência num mesmo espaço da civilização e da barbárie seriam o aspecto mais magnífico do mundo atual. As rupturas, na perspectiva pós-moderna, ainda que expressassem estraçalhamentos mútuos, acabariam se acomodando, sendo integradas, portanto. Inerente a esse quadro trágico, a postura do homem deve ser a do cético, no sentido daquele que se retira de cena e recusa a se engajar, em que cada um deve julgar o espetáculo apenas em termos de quão espetacular ele é. Deve se suspender a crença, bem como a descrença. À descrença na possibilidade de se definir um "quadro epistemológico permanente de pesquisa" corresponde uma prática em que se privilegiam ações apenas táticas, ou seja, a nível local, pequenas - micro revoluções que seriam as únicas possíveis. A este respeito a analise de David Harvey iii mostra o engodo de tais empreendimentos revolucionários, que de certo modo estaria sempre sendo diluído no próprio sistema capitalista. Esses 
movimentos, por mais eficazes que pareçam ser, sempre chocar-se-iam com um paradoxo que se apresenta como irresolúvel:

"Porque não somente a comunidade do dinheiro, aliado com um espaço e um tempo racionalizados, os define num sentido oposicional, como também os movimentos têm de enfrentar a questão do valor e de sua expressão, bem como da organização necessária do espaço e do tempo apropriada à sua própria reprodução. Ao fazê-lo, eles se abrem necessariamente ao poder dissolutivo do dinheiro, assim como às cambiantes definições de espaço e de tempo que surgem por meio da dinâmica da circulação do capital. Em suma, o capital continua a dominar, e o faz, em parte, graças ao domínio superior do espaço e do tempo, mesmo quando os movimentos de oposição obtêm por algum tempo o controle de um lugar particular. As"alteridades" e "resistências regionais" que a política pós-moderna enfatiza podem florescer num lugar particular. Mas, com muita freqüência, estão sujeitas ao poder que o capital tem sobre a coordenação do espaço fragmentado universal e da marcha do tempo histórico global do capitalismo, que está além do alcance de qualquer delas". iv

Destaca-se, sobretudo, a negação de qualquer possibilidade e eficácia de um saber globalizante. Isso, de certo modo, nos recorda o que escreveu Harvey (1992), de que a retórica pós-moderna "evita o enfrentamento das realidades da economia política e das circunstâncias do poder global”. Essa atitude é perigosa. As micro revoluções esvanecer-se-iam se não agregassem a uma luta geral de emancipação da humanidade, cujo eixo básico seria a batalha em torno da libertação da classe trabalhadora.

A proposta de uma única ciência deve ser pensada na perspetiva acima. Ainda que Marx concebesse a experiência dos sentidos como base única de toda ciência, ele admitiu uma correlação dialética e não hierárquica entre as ciências naturais e as ciências do homem: "a ciência da natureza incorporaria a ciência do homem e a ciência do homem incorporaria a ciência da natureza; dessa incorporação surgiria uma ciência única: a ciência natural humana"v A proposta do Direito como "ciência da totalidade concreta"vi refutaria também quaisquer tentativas de ecletismo, que significava conciliar as diversas compartimentações apresentadas pelas diversas propostas ontológicas e epistemológicas. Nada mais caricatural, nesta perspectiva, do que uma proposta de anarquismo metodológico, que se não procura conciliar e harmonizar diferentes tendências, consentiria, contudo, uma possibilidade de convivência entre tendências dispares, competindo entre si, numa espécie de 
darwinismo epistêmico. A unidade do conhecimento vincular-se-ia à unidade da práxis.

A proposta da 'ciência única' é uma forma de compreensão integrada do homem, da sociedade e da natureza, num movimento em que não só o próprio homem e a sociedade constituir-se-iam em produtos humanos, mas também a natureza, como base da experiência humana e de um elemento de sua realidade, tornou-se humanizada para o homem. Acrescenta-se a isso que se trata de pensar a realidade de modo global e concreto.

O que temos é que a ciência, enquanto atividade humana, não pode renegar seu caráter histórico de práxis libertadora ou de alienação utilitária, em que estaria a serviço da acumulação do capital. A idéia de "ciência una" nos possibilita pensar as atividades cientifica das mais diversas 'especialidades' como um fazer integrado historicamente, quer para maximizar os lucros do capital, quer para contribuir no sentido de liberar o gênero humano, que nas condições atuais do capitalismo significaria contribuir no sentido da luta pela emancipação da classe trabalhadora. Portanto, nenhum saber é neutro, mesmo quando sua aplicação restringe o mais ínfimo dos aperfeiçoamentos de uma máquina. Tanto o saber como a máquina estão inseridos num contexto cuja compreensão nos revelaria as suas implicações históricas. Nesse sentido, as informações precisas e atualizadas são fundamentais para a acumulação do capital. O saber é uma mercadoria.

O acesso ao conhecimento científico e técnico é fundamental na luta competitiva entre capitalistas, mas ele o é também no sentido da luta de classes. Nesse sentido, a "ciência única" tornar-se-ia na forma básica, para se compreender, as várias praticas locais - do saber e do fazer - não como singularidades imediatas, mas, sobretudo como integradas numa concretude histórica, cuja visão de conjunto - meta narrativa - nos possibilitaria compreender, de modo crítico, a quem serve determinadas opções metodológicas e, sobretudo, no que se refere à escolha dos objetos - conforme a finalidade de uma produção de um saber local, aplicável, conversível em tecnologia.

Curiosamente, hoje em dia, há certa moda 'ideológica' de que estaríamos nos tempos dos fins: não da história, da ideologia, mas do trabalho, da ciência, da guerra. O mercado parece ter sido um dos únicos conceitos bem 
sucedidos, ou eficientíssimos, pois ninguém parece ter coragem de sepultá-lo ou mesmo de antever a possibilidade de sua morte. Com o acirramento da concentração de rendas e as novas formas de exploração, que mais do que nunca contam com a exclusão social e todas novas formas de perversidades sociais: guetos, violência entre gangues, máfias e todo o circuito perverso da "economia informal" etc., e, sobretudo com os retrocessos em termos de direitos trabalhistas.

O trabalho até o chamado maquinismo, dependia do lento e custoso esforço dos homens e suas ferramentas, de ocupação plena, porém de oferta insuficiente, demanda em crescimento e economia elementar. A mecanização chegou para simplificar a tarefa - principalmente de esforço físico - já que poderiam ser cumpridos objetivos mais ambiciosos, principalmente pela possibilidade de produzir maior quantidade de bens em igual tempo. Aqui se firmou o primeiro passo contra a ocupação do trabalho humano, já que o impacto da grande quantidade de demanda insatisfeita não fora tão brusco. A partir deste acontecimento, o centro da economia começa a ser deslocado do campo para a cidade exigindo maior adestramento de pessoal para o uso de ferramentas mais sofisticadas.

O chamado "Taylorfordismo" se converteu em uma forma de organizar a produção que dominou o século $X X$, permitindo a produção em massa $\mathrm{e}$ pondo à disposição dos consumidores, abundante quantidade de bens manufaturados. Logo em seguida, a tecnologia trouxe, em uma segunda etapa (pós-Taylorfordismo), uma nova meta, que consistiu em seguir produzindo maior quantidade bens em igual ou menor tempo e com menor custo. Assim o "Custo do trabalho" vinculou-se não só relação com a montante do salário que recebiam os trabalhadores, mas também com a "produtividade".

A esta nova etapa os estudiosos chamaram de "Toyotismo" ou pósindustrial, em virtude da cópia do modelo de produção dos japoneses, altamente técnicos e despersonalizados. Dentro deste modelo de campo industrial, o ingresso da informática tem produzido transformações que foram muito mais profundas e intempestivas que as ocorridas com a mecanização, já que em poucos anos o computador acelerou a tal ponto a economia, que já não cabem dúvidas que o terceiro milênio será de seu governo. 
O certo é que, por uma ou outra causa, se tem potenciado o "canibalismo ocupacional" (6), já que, a desocupação provoca uma Luta de classes: os que estão com emprego e os desempregados.

O problema do Direito do Trabalho é motivado pela conjuntura econômica, que em verdade é a maior fonte geradora de incertezas.

Atualmente podemos questionar a própria metodologia empregada no estudo do Direito do Trabalho, já que deve incluir o estudo do direito ao trabalho (pertencente a política social), dentro de uma ramo específico que busque desenvolver e aprimorar as relações existentes com o máximo de equilíbrio (justiça social), tentando produzir um espaço necessário ao estudo do direito ao emprego, e ampliando o horizonte do direito do trabalho, bem como seu equilíbrio e coerência já que há necessidade de novos elementos (campos de estudo) que restaurem a paz.

O problema ocupacional é e será - já no início deste milênio - o produtor dos maiores inconvenientes não só para os governos, e sim para a sociedade como um todo. O conflito já está instalado e não se vislumbram soluções a curto nem médio prazo. Por tal razão, faz-se necessário projetar em longo prazo mecanismos de solução para este problema, a fim que as necessidades mínimas insatisfeitas de uns e o ócio mal canalizado de outros, não continuem sepultando a paz social.

Esta visão da realidade mostra uma comunidade infeliz, com valores altamente depreciados, e um alto deterioramento da auto-estima individual, fruto dos diários ataques sofridos que atingem sobremaneira a dignidade humana e baixam a "cotação da solidariedade". É, nada mais nada menos, que a substituição do homem pela máquina. Portanto, alguma solução deve ser tentada ou buscada, já que sem a matéria-prima (o emprego) não tem sentido o estudo do direito do trabalho e da seguridade social. Sem contar com o risco para o próprio direito como um todo bem como para a vida em sociedade. Em nosso entender, o primeiro passo a ser dado seria no sentido de estabelecer um rol prioritário de diálogos sociais que buscassem soluções alternativas no campo do voluntarismo, e logo em seguida direcioná-lo para o diálogo-ação consensuado.

É dizer, estamos na presença de uma situação de desemprego estrutural que nos expõe a um permanente perigo à paz social e sobre o qual 
os economistas e o poder político não têm tomado verdadeira consciência. Por tal razão, se deve responder a tal conformismo com uma transformação radical que implique avançar sobre suas causas e, desse modo, progredir na justiça com uma nova estrutura que aproveite o que a anterior tem de mais eficaz.

O Direito, como toda a ferramenta, deve estar a serviço do homem, e a informática deve subordinar-se ao direito e este deve prever que não deve relegar o homem. Porém, o direito por si só não pode criar condições sociais (como por exemplo, que não haja mais desemprego) sem que resulte imprescindível a transformação cultural que propugna. O homem, novamente e como sempre, é o centro da cena e principal ator das transformações.

\section{REFERÊNCIAS:}

DAVIS, B., "Technology Brokers Meet Limited Success. High Techology. (Oct. 1985).

ETZKOWITZ, H. "Entrepreneurial science in the academy: a case of the transformation of norms", in Social Problems, vol 36, n. 1, 1989.

FÁVERO, M. L. A “ A Universidade Brasileira em busca de sua identidade” . Petrópolis. R.J. Ed. Vozes.1979.

FRIEDMAN, M. Capitalismo e liberdade. Brasil. Ed. Arte Nova. 1977.

HAYEK, F. O caminho da servidão, Porto Alegre, Ed. Globo, 1977, $2^{a}$ edição.

HARVEY, David. Condição pós-moderna. S.P. Edições Loyola, 1992.

HUNT \& SHERMAN. História do Pensamento Econômico. R.J. Ed. Vozes. 1977.

IANNI, O. Teorias da globalização. RJ. Ed. Civilização Brasileira, 1995.

A sociedade global. RJ. Ed. Civilização Brasileira, 1999.

A era do globalismo. RJ. Ed. Civilização Brasileira, 1996.

MARX, KARL. Contribuição a crítica da economia política. S.P. Livraria Martins Fontes.1977.

. "Teses sobre Feuerbach.(III)", In Marx, Karl e Engels, Friedrich. TEXTOS.

SP. Edições Sociais, 1977, s/d.v.03. p.118.

O Capital. S.P. Ed. Nova Cultural. 1985, vol III.

' MARX, K, A ideologia alemã. S.P. Hucitec, 1989, p. 72. 
ii A retórica liberal tenta opor essas tendências como extremos irreconciliáveis: "Fundamentalmente só há dois meios de coordenar as atividades econômicas de milhões. Um deles é a direção central utilizando a coerção - a técnica do Exército e do Estado totalitário moderno. O outro é a cooperação voluntária dos indivíduos - a técnica do mercado ". M. FRIEDMAN, Capitalismo e liberdade. S.P. Ed. Artenova, p. 21".

iii HARVEY, David. Condição pós-moderna. S.P. Edições Loyola, 1992.

iv Id. ib. , p. 217-8.

vid. ib., p. 361.

vi“O concreto é concreto porque é a síntese de muitas determinações, isto é, unidade do diverso. Por isso o concreto aparece no pensamento como o processo da síntese, como resultado, não como ponto de partida, ainda que seja o ponto de partida efetivo e, portanto, o ponto de partida também da intuição e da representação. No primeiro método, a representação plena volatiliza-se em determinações abstratas, no segundo, as determinações abstratas conduzem à reprodução do concreto por meio do pensamento ". Marx, K. Para a crítica da economia política. Os pensadores. Nova Cultural. Volume I.p. 16-7". 